\title{
Serum Indicators of Oxidative Damage from Embedded Metal Fragments in a Rat Model
}

\author{
John F. Kalinich $(\mathbb{D}$, Vernieda B. Vergara, and Jessica F. Hoffman \\ Internal Contamination and Metal Toxicity Program, Armed Forces Radiobiology Research Institute, \\ Uniformed Services University, Bethesda, Maryland 20889-5648, USA \\ Correspondence should be addressed to John F. Kalinich; jkalinich@som.umaryland.edu
}

Received 8 November 2021; Revised 4 December 2021; Accepted 4 January 2022; Published 2 February 2022

Academic Editor: Demetrios Kouretas

Copyright (c) 2022 John F. Kalinich et al. This is an open access article distributed under the Creative Commons Attribution License, which permits unrestricted use, distribution, and reproduction in any medium, provided the original work is properly cited.

\begin{abstract}
Injuries suffered in armed conflicts often result in embedded metal fragments. Standard surgical guidance recommends leaving embedded fragments in place except under certain circumstances in an attempt to avoid the potential morbidity that extensive surgery often brings. However, technological advances in weapon systems and insurgent use of improvised explosive devices now mean that practically any metal can be found in these types of wounds. Unfortunately, in many cases, the long-term toxicological properties of embedded metals are not known, further complicating treatment decisions. Because of concerns over embedded metal fragment injuries, the U.S. Departments of Defense and Veterans' Affairs developed a list of "metals of concern" for these types of injuries. In this study, we selected eight of these metals including tungsten, nickel, cobalt, iron, copper, aluminum, lead, and depleted uranium to investigate the long-term health effects using a rodent model developed in our Institute to study embedded fragment injuries. In this report, we show that metals surgically implanted into the gastrocnemius muscle of laboratory rats to simulate a shrapnel wound induce a variety of cytokines including IFN- $\gamma$, IL- 4 , IL5 , IL-6, IL-10, and IL-13. TNF- $\alpha$ and KC/GRO were not affected, and IL- $1 \beta$ was below the limit of detection. Serum levels of C-reactive protein were also affected, increasing with some metals and decreasing with others. The TBARS assay, an assessment of lipid peroxidation, demonstrated that implanted aluminum and lead increased markers of lipid peroxidation in serum. Taken together, the results suggest that serum cytokine levels, as well as other indicators of oxidative damage, may prove useful in identifying potential adverse health effects of embedded metals.
\end{abstract}

\section{Introduction}

Metals can be internalized by several routes including ingestion and inhalation and through wounds. The health effects of inhalation and ingestion of metals have been well studied; however, the effects of embedded metal fragments have received less attention. One of the reasons for this was the long-time assumption that embedded metals, especially those from war wounds, were biologically inert [1]. Occasional reports in the scientific literature describing the health effects of metal fragment wounds suffered in battle many years prior suggested that this was not always the case $[2-8]$. Because of the risk of morbidity that excessive surgery can bring, standard surgical guidance is to leave embedded fragments in place unless they are easily accessible or may present a life-threatening health issue in the future [9]. Technological improvements in armor protection and advancements in battlefield medicine now mean that injuries that were once inherently fatal are now survivable. However, this results in a cohort of individuals that now carry retained metal fragments potentially for the rest of their lives. The extent of the issue was made clear by the U.S. Department of Defense which estimated that there are over 40,000 U.S. military personnel with retained metal fragments as a result of their service in the Iraq and Afghanistan conflicts [10]. In many cases, the toxicological and carcinogenic properties of these metals are not known. As a result, the U.S. Departments of Defense (DoD) and Veterans Affairs (DVA) developed a list of military-relevant "metals of concern" with respect to embedded metal fragments $[11,12]$ with the 
intent of identifying those individuals with embedded fragments, the metal or metals retained, and their follow-up long-term health care.

Adverse health effects due to embedded metals are not limited to war injuries. Published case reports also described workplace injuries with embedded metal fragments from lawnmower and chainsaw blades that over time resulted in granuloma formation $[13,14]$. The failure of implanted medical and prosthetic devices such as artificial knees and metal-onmetal hip replacements has also occasionally resulted in health issues $[15,16]$. Often times, additional surgery is required to replace the device although there have been cases where the device failure has resulted in the death of the patient [17].

The ability to identify impending health risks as a result of embedded metals is limited. As noted in the above citations, most of the adverse health effects induced by embedded metals from battlefield wounds were recognized only when a tumor or granuloma formed. A protocol by which potential adverse health outcomes could be identified early enough so that treatment plans, including more extensive surgical removal of the embedded fragment, could be initiated would be useful. While biomarkers of adverse health issues have not been thoroughly investigated with respect to embedded metal fragments of military-relevant metals, there are numerous reports in the literature on the induction of cytokines and indicators of oxidative stress in patients with failed implanted medical devices, most notably, metal-on-metal hip replacements. For example, Christiansen et al. reported on the cytokine profile of patients with aseptic loosening of hip replacements [18]. In their study, the proinflammatory cytokines IL- $1 \beta$, IL- 2 , IL- 8, IFN- $\gamma$, and TNF- $\alpha$ were significantly increased as was the antiinflammatory cytokine, IL-10. Similar results were seen for patients with metal-on-polyethylene hip replacements, as well as those with total knee replacements $[19,20]$. Changes in cytokine expression and the induction of oxidative damage to DNA, lipids, and proteins were also seen in metal exposure via inhalation [21]. Taken together, these results suggest that a battery of assessments, both cytokine levels and oxidative damage markers, might be useful in detecting early adverse changes induced by embedded fragments of military-relevant metals.

Using a rodent model developed in our Institute to study the health effects of embedded metal fragments, we investigated the effect of 8 metals chosen from the DoD and DVA list of "metals of concern" on cytokine levels and indicators of oxidative stress in the serum of laboratory rats implanted with metals for up to 12 months. This research is part of a larger collaborative effort with the Department of Veterans' Affairs Medical Center in Baltimore, Maryland, the University of Maryland School of Medicine, and the University of Kentucky to study the potential health effects of embedded metals in our rodent model alongside an expanded human study with military service personnel with retained metal fragments.

\section{Materials and Methods}

2.1. Animals and Animal Husbandry. The Armed Forces Radiobiology Research Institute (AFRRI) Institutional Animal Care and Use Committee (IACUC) approved all animal use prior to initiation under protocol number 2016-05-006. All procedures were conducted in compliance with the Guide for the Care and Use of Laboratory Animals [22] in an Association for Assessment and Accreditation of Laboratory Animal Care- (AAALAC-) accredited facility. Two hundred and eighty-eight male Sprague-Dawley (Rattus norvegicus) rats, approximately 30 days old and weighing 75-100 g, were obtained from Envigo (Barrier 208A, Frederick, MD, USA). After arriving at the vivarium, animals were allowed to acclimate for at least two weeks. Rats were pairhoused throughout the study in plastic microisolator cages with filter tops. Teklab Sani-Chips (Envigo) were used as bedding and changed 2-3 times per week. Vivarium rooms were maintained at $21 \pm 2^{\circ} \mathrm{C}$ with $30-70 \%$ humidity. A $12: 12 \mathrm{~h}$ light: dark cycle was maintained with lights on at 0600. Rats were fed a standard rodent chow (Teklad Global Rodent Diet 8604, Envigo) with water available ad libitum.

2.2. Experimental Design. Our Institute previously developed a rodent model to study the health effects of embedded metal fragments, such as those suffered in a shrapnel wound [23]. In this study, we used that model to investigate the effects of eight military-relevant metals including tungsten (W), nickel $(\mathrm{Ni})$, cobalt $(\mathrm{Co})$, iron $(\mathrm{Fe})$, copper $(\mathrm{Cu})$, aluminum $(\mathrm{Al})$, lead $(\mathrm{Pb})$, and depleted uranium (DU). Tantalum (Ta) was used as a control for any changes resulting from the surgical procedure or due to the presence of a foreign material in the muscle. Tantalum is considered inert and has been used for implanted prosthetic devices [24-26]. Earlier investigations have shown no differences between naïve and tantalumimplanted rats [27-29]. Thus, the total number of rats needed for the study could be reduced and the ARRIVE guidelines met [30]. The rats were randomly assigned to one of the nine metal implantation groups with $n=8$ per metal. In the metal groups, surgery was conducted in 4 different cohorts: 1-, 3-, 6-, or 12-month postimplantation surgery (i.e., "time from implant"). A total of 288 rats ( $n=8 \times 9$ metal groups $\times 4$ cohorts) were used in the study.

2.3. Metal Pellets. Metal pellets for implantation were obtained from Alfa Aesar (Ward Hill, MA, USA) with the exception of DU which was purchased from Aerojet Ordnance (Jonesboro, TN, USA). All pellets were cylinders $1 \mathrm{~mm}$ in diameter by $2 \mathrm{~mm}$ in length. Prior to implantation, pellets were cleaned and chemically sterilized as previously described [31].

2.4. Metal Pellet Implantation Surgery. Metal pellets were surgically implanted bilaterally in the gastrocnemius muscle of rats as previously described $[32,33]$. Briefly, animals were initially anesthetized using isoflurane (Baxter Healthcare, Deerfield, IL, USA) in an induction chamber. Anesthesia was then maintained throughout the surgical period using a nose cone with a scavenger/recapture system. The surgical site was clipped, swabbed with $70 \%$ isopropanol, and cleansed with betadine (Purdue Pharma LP, Stamford, CT, USA). Prior to surgery, a prophylactic dose of buprenorphine (0.05-0.1 mg/kg, s.c., Reckitt and Colman, Hull, UK) was administered to serve as an analgesic. For animal 


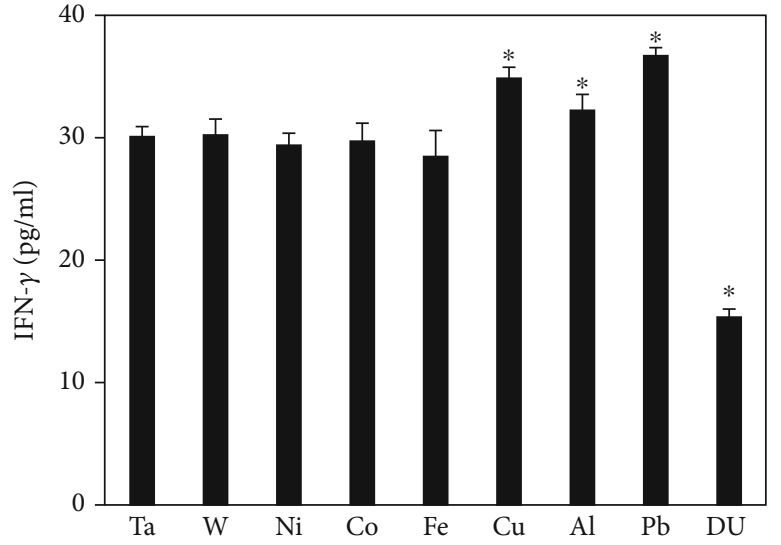

(a)

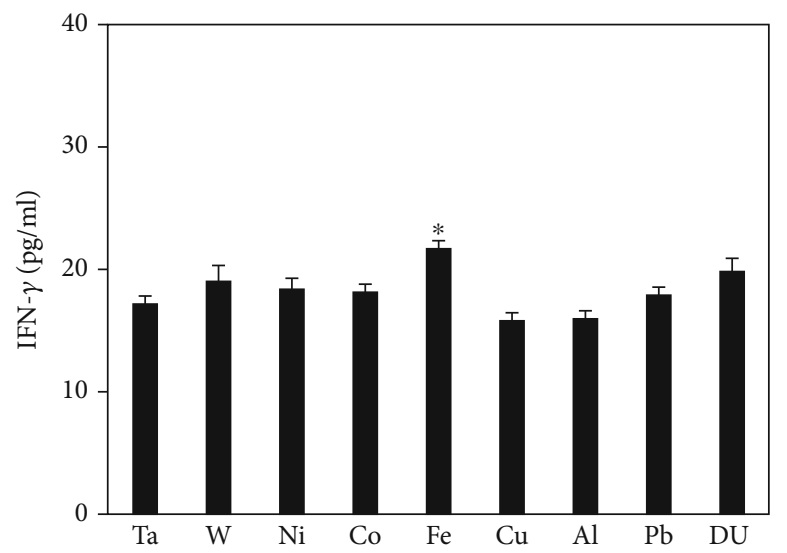

(c)

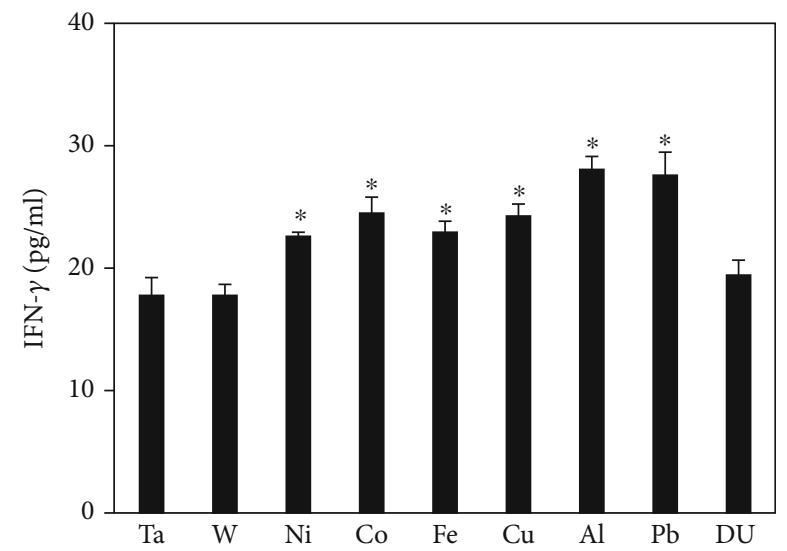

(b)

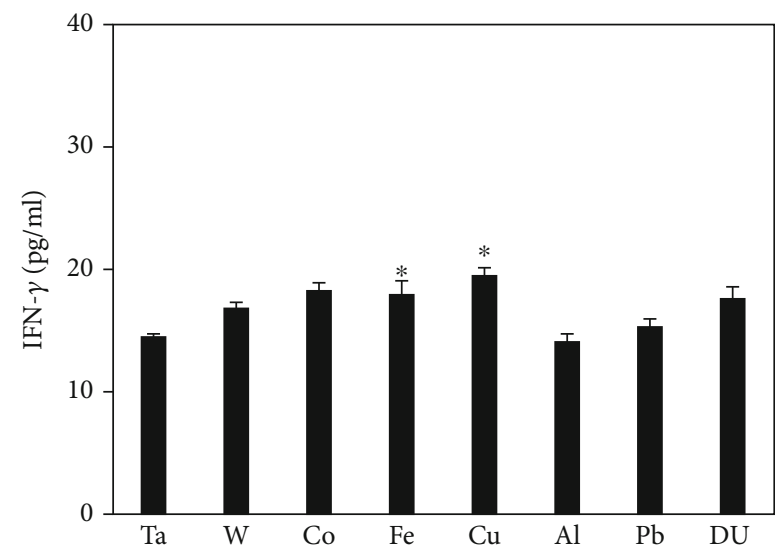

(d)

FIGURE 1: IFN- $\gamma$ levels in serum from metal-implanted rats: (a) 1 month postimplantation; (b) 3 months postimplantation; (c) 6 months postimplantation; (d) 12 months postimplantation. Data represent the mean of 8 independent determinations. Error bars are standard error of the mean. Note: the $12 \mathrm{M} \mathrm{Ni}$ cohort was euthanized at approximately $6 \mathrm{M}$ as a result of tumor formation. An $*$ indicates a post hoc test between Ta- and target-metal animals at that time point $(p<0.05)$.

identification purposes, two methods were employed. A small transponder (Electronic Lab Animal Monitoring System, Bio-Medic Data Systems, Seaford, DE, USA) was injected subcutaneously in the middorsal thoracic region. The transponders were programmed with a unique animal identification number that can be read with a low-power radio frequency scanner. An ear punch system was used as the second backup identification system in the event of transponder failure. For pellet implantation, using an aseptic technique, a small incision approximately $5 \mathrm{~mm}$ in length was made through the skin of each hind leg to expose the gastrocnemius muscle. Each gastrocnemius muscle was implanted with two sterile pellets spaced approximately $1.5 \mathrm{~mm}$ apart on the lateral side of the muscle by placing the sterile pellet in a 16-gauge needle. Using a specially designed plunger placed inside the needle, the needle was inserted into the gastrocnemius and the plunger depressed forcing the pellet into the muscle. Tissue adhesive (VetBond; 3M Corporation, St. Paul, MN, USA) was used to seal the incision. After surgery, rats were closely monitored until ambulatory. The surgery sites were examined daily for two weeks to assess for signs of inflammation, infection, and local metal toxicity and, after that time, weekly for the duration of the study.
2.5. Euthanasia and Sample Collection. Upon reaching their experimental endpoint or when indicated by guidelines approved by the IACUC, rats were deeply anesthetized using isoflurane and blood was collected for hematological analysis as well as for serum isolation. Following blood collection, the rats were humanely euthanized under deep isoflurane by exsanguination and confirmatory pneumothorax as per the guidelines of the American Veterinary Medical Association [34]. A complete gross pathology examination was conducted, and a variety of tissues were collected for further examination as has been described in earlier publications [32, 33].

2.6. Serum Preparation. Blood was collected in serum separator tubes (Becton-Dickinson, Franklin Lakes, NJ, USA), and the tubes were inverted 5 times and then allowed to sit undisturbed for $30 \mathrm{~min}$ at room temperature. The tubes were centrifuged at $1200 \times g$ for $10 \mathrm{~min}$ at room temperature. The serum was aliquoted into $1.5 \mathrm{ml}$ centrifuge tubes and stored at $-80^{\circ} \mathrm{C}$ until analyzed.

2.7. Serum Proinflammatory Markers. Serum levels of interferon (IFN-) $\gamma$, interleukin- (IL-) $1 \beta$, IL-4, IL-5, IL6, KC/GRO, IL-10, IL-13, and tumor necrosis factor- 




(a)

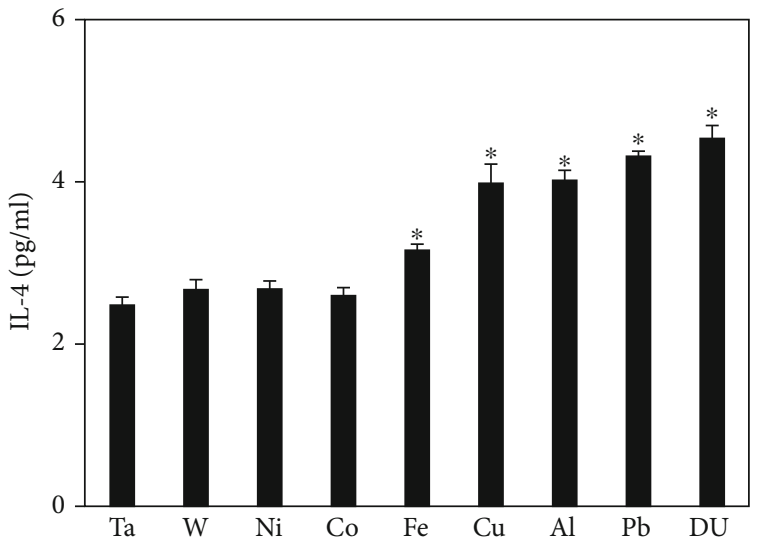

(c)

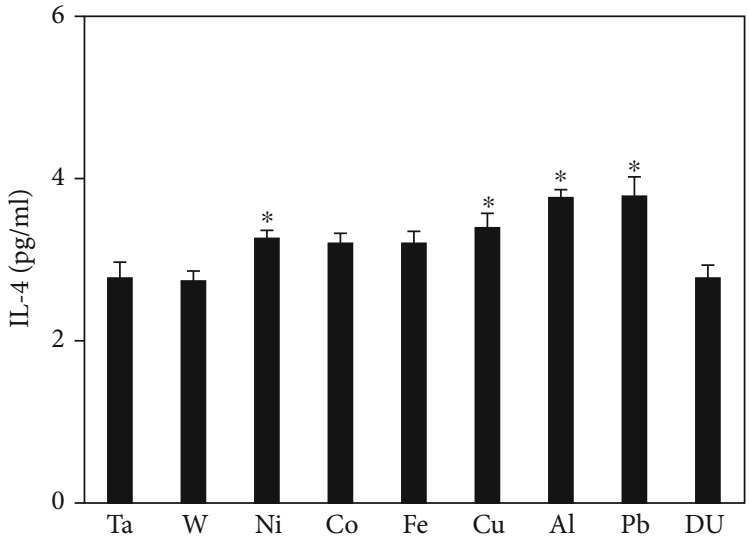

(b)

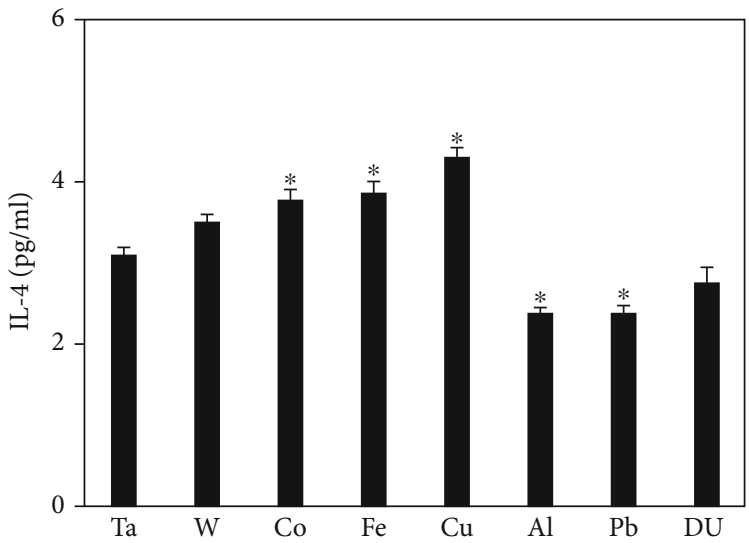

(d)

Figure 2: IL-4 levels in serum from metal-implanted rats: (a) 1 month postimplantation; (b) 3 months postimplantation; (c) 6 months postimplantation; (d) 12 months postimplantation. Data represent the mean of 8 independent determinations. Error bars are standard error of the mean. Note: the $12 \mathrm{M} \mathrm{Ni}$ cohort was euthanized at approximately $6 \mathrm{M}$ as a result of tumor formation. An $*$ indicates a post hoc test between Ta- and target-metal animals at that time point $(p<0.05)$.

(TNF-) $\alpha$ were determined using the rat serum proinflammatory panel-2 kit from Meso Scale Discovery (kit \# K15059D, Rockville, MD, USA). The technique uses a special electrode-containing 96-well plate coated with the appropriate capture antibodies to bind the analytes of interest. Addition of detection antibodies conjugated to a proprietary chemiluminescence tag allows quantitation of the targeted proteins using a Meso Scale Discovery SQ120 QuickPlex Reader. The instrument applies a voltage to the electrodes in the plate that causes the tagged detection antibodies to emit light. The intensity of the light provides a quantitative measure of the analytes in the serum sample, with concentrations determined by comparison to a standard curve using the Meso Scale Discovery Workbench software. The reported lower limits of detection of the procedure are as follows: IFN $-\gamma: 0.65 \mathrm{pg} / \mathrm{ml}$; IL-1 $\beta: 4.26 \mathrm{pg} / \mathrm{ml}$; IL-4: $0.52 \mathrm{pg} / \mathrm{ml}$; IL-5: $12.8 \mathrm{pg} / \mathrm{ml}$; IL-6: $3.16 \mathrm{pg} / \mathrm{ml}$; KC/GRO: $0.77 \mathrm{pg} / \mathrm{ml}$; IL-10: $1.42 \mathrm{pg} / \mathrm{ml}$; IL-13: $0.96 \mathrm{pg} / \mathrm{ml}$; and TNF- $\alpha: 0.23 \mathrm{pg} / \mathrm{ml}$.

2.8. C-reactive Protein Assay. Serum levels of C-reactive protein were determined using the Rat C-Reactive Protein ELISA kit (kit \#ab108827, Abcam, Cambridge, MA, USA).
Briefly, serum samples were diluted to $1: 60,000$ with the sample diluent provided in the kit. Samples and standards (50 $\mu \mathrm{l} /$ well) were added to a 96-well antibody-coated plate and incubated at room temperature with shaking $(250 \mathrm{rpm}$, Incubating Microplate Shaker, VWR, Radnor, PA, USA) for $2 \mathrm{~h}$. After washing, a biotinylated detector antibody was added and incubation continued for $1 \mathrm{~h}$ at room temperature with shaking $(250 \mathrm{rpm})$. The plate was then washed, the streptavidin-peroxidase conjugate was added, and the plate was incubated for $20 \mathrm{~min}$ at room temperature with shaking at $250 \mathrm{rpm}$. After stopping the reaction, the plate was immediately read at $450 \mathrm{~nm}$ using a plate reader (BioTek Synergy Model H1M Multimodal Plate Reader with GEN5 Software, BioTek Instruments, Winooski, VT, USA). The concentration of C-reactive protein in the samples was determined by comparing the absorbance readings of the samples to those from a standard curve. The lower limit of detection of the assay is $0.25 \mathrm{ng} / \mathrm{ml}$.

2.9. Thiobarbituric Acid Reactive Substance (TBARS) Assay. Lipid peroxidation was monitored using the thiobarbituric acid reactive substance (TBARS) assay kit from Cayman 


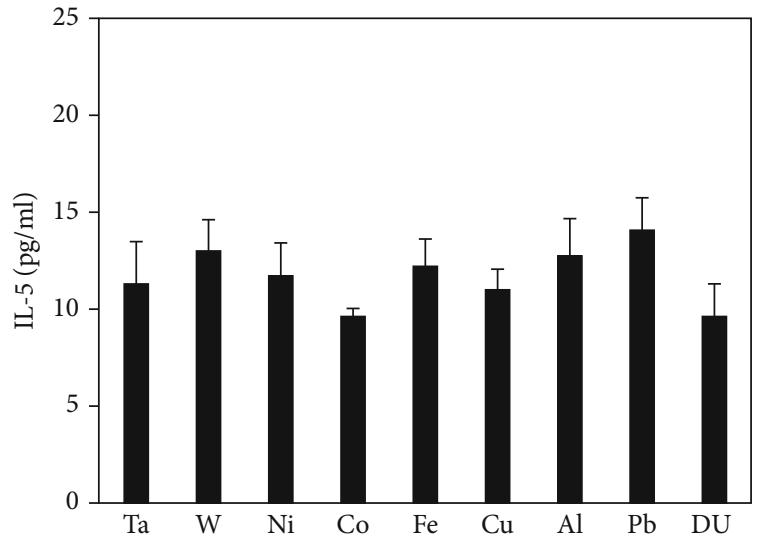

(a)

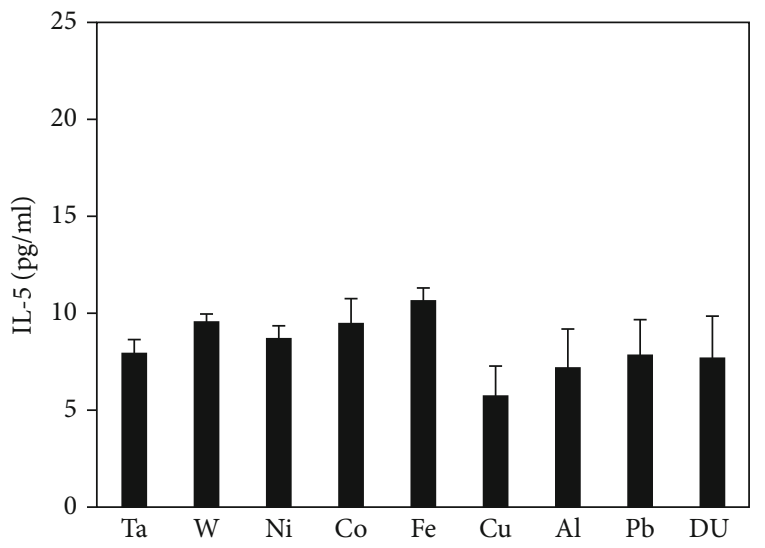

(c)

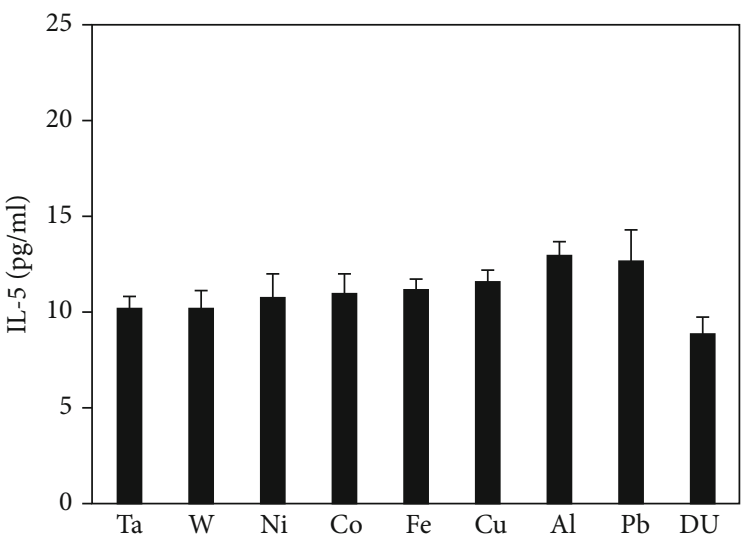

(b)



(d)

FIgURE 3: IL-5 levels in serum from metal-implanted rats: (a) 1 month postimplantation; (b) 3 months postimplantation; (c) 6 months postimplantation; (d) 12 months postimplantation. Data represent the mean of 8 independent determinations. Error bars are standard error of the mean. Note: the $12 \mathrm{M} \mathrm{Ni}$ cohort was euthanized at approximately $6 \mathrm{M}$ as a result of tumor formation. An $*$ indicates a post hoc test between Ta- and target-metal animals at that time point $(p<0.05)$.

Chemical (kit \#700870, Ann Arbor, MI, USA). The TBARS assay measures the amount of malondialdehyde (MDA), a naturally occurring product of lipid peroxidation, in a sample by reacting it with thiobarbituric acid (TBA). The MDA-TBA adduct can then be detected either colorimetrically or fluorometrically. Briefly, $100 \mu \mathrm{l}$ of sample or standard was placed in a $1.5 \mathrm{ml}$ centrifuge tube; $100 \mu \mathrm{l}$ of $10 \%$ trichloroacetic acid was added followed by $800 \mu \mathrm{l}$ of "Color Reagent" (TBA in acetic acid/sodium hydroxide, supplied in the kit). After vortexing, the tubes were placed in a $95^{\circ} \mathrm{C}$ heat block for $60 \mathrm{~min}$ and then placed in an ice bath for $10 \mathrm{~min}$. The tubes were centrifuged at $1600 \times g$ for $10 \mathrm{~min}$, and $200 \mu \mathrm{l}$ of the resulting supernatant, in duplicate, was removed and placed in a black plate for fluorometric analysis. The BioTek Synergy Model H1M Multimodal Plate Reader was used with an excitation wavelength of $532 \mathrm{~nm}$ and an emission wavelength of $585 \mathrm{~nm}$ to assess the concentration of the MDA-TBA adduct in both the standards and the samples. The lower limit of detection of the assay for MDA is $0.01 \mu \mathrm{M}$.

2.10. Advanced Oxidative Protein Product (AOPP) Assay. Serum samples were analyzed for advanced oxidative protein products using the OxiSelect AOPP Assay Kit (kit \# STA-318, Cell Bio- labs, Inc., San Diego, CA, USA). Serum samples were diluted to $1: 20$ with the assay diluent included in the kit, and $200 \mu \mathrm{l}$ of the prepared samples was added per well to a 96-well plate. A chloramine reaction initiator, provided in the kit, was added to each well and the plate incubated for $5 \mathrm{~min}$ at room temperature with shaking $(250 \mathrm{rpm})$. The reaction was then terminated and the plate read at $340 \mathrm{~nm}$ using the BioTek Synergy Model H1M Multimodal Plate Reader. The AOPP concentrations in the serum samples were determined by comparing to a standard curve prepared using chloramine-T. The lower limit of detection is approximately $1.25 \mu \mathrm{M}$.

2.11. Glutathione Assay. Glutathione levels in the collected serum samples were determined using the DetectX Glutathione Fluorescent Detection Kit (kit \# K006, Arbor Assays, Ann Arbor, MI, USA). Initially, serum samples were diluted with an equal volume of ice-cold 5\% 5-sulfo-salicylic acid (catalog \# S2130, Sigma Chemical Co., St. Louis, MO, USA) and left on ice for $10 \mathrm{~min}$. Samples were centrifuged for $10 \mathrm{~min}$ at $21,000 \times \mathrm{g}$ after which $30 \mu \mathrm{l}$ of the resulting supernatant was carefully removed, added to a fresh centrifuge tube, and diluted with Assay Buffer provided in the kit. The final sample dilution was 1:25. Diluted samples 


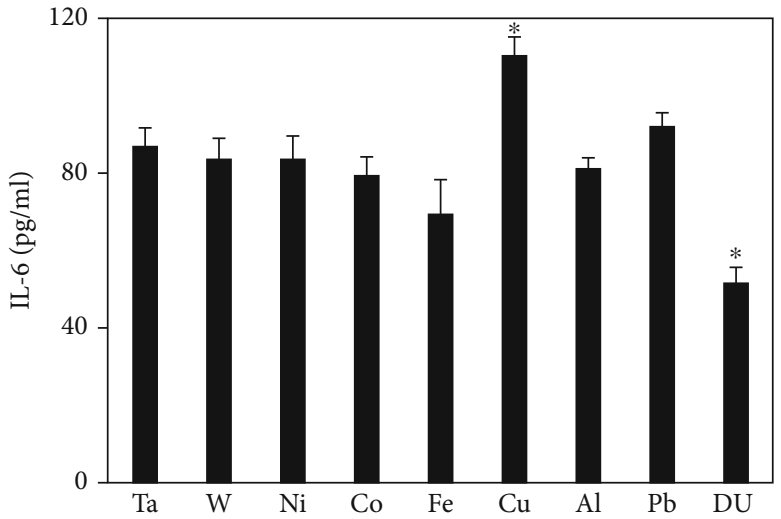

(a)

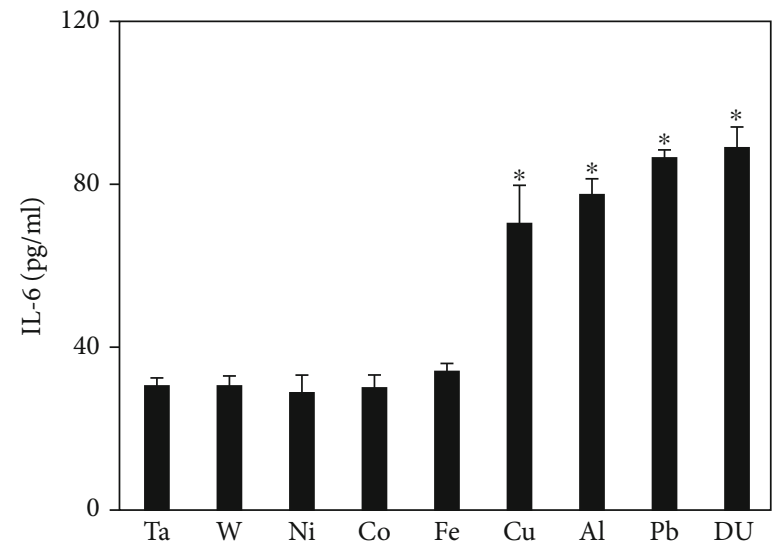

(c)



(b)

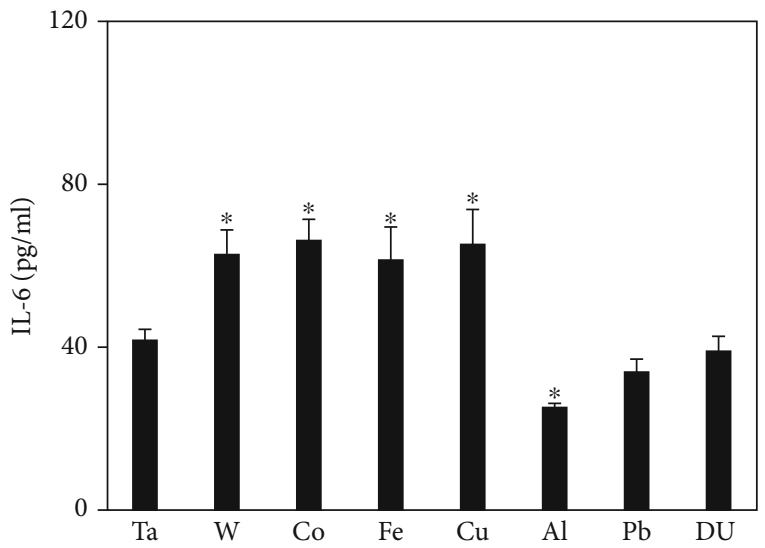

(d)

FIGURE 4: IL-6 levels in serum from metal-implanted rats: (a) 1 month postimplantation; (b) 3 months postimplantation; (c) 6 months postimplantation; (d) 12 months postimplantation. Data represent the mean of 8 independent determinations. Error bars are standard error of the mean. Note: the $12 \mathrm{M} \mathrm{Ni}$ cohort was euthanized at approximately $6 \mathrm{M}$ as a result of tumor formation. An $*$ indicates a post hoc test between Ta- and target-metal animals at that time point $(p<0.05)$.

and standards were added to the plate at $50 \mu \mathrm{l} /$ well followed by $25 \mu \mathrm{l}$ of ThioStar $^{\mathrm{TM}}$ Diluent provided in the kit. After a $15 \mathrm{~min}$ incubation at room temperature, fluorescence was read using the BioTek Synergy Model H1M Multimodal Plate Reader with excitation at $370 \mathrm{~nm}$ and emission at $510 \mathrm{~nm}$. This represents the free glutathione concentration. After addition of the kit-provided "Reaction Mixture" $(25 \mu \mathrm{l} /$ well $)$ and a second $15 \mathrm{~min}$ room temperature incubation, the plate was again read using the conditions described above. This reading represents the total glutathione concentration. The reported lower limits of detection are $38 \mathrm{nM}$ and $42 \mathrm{nM}$ for the free and total glutathione levels, respectively.

2.12. Statistical Analysis. Assay data are expressed as the mean of 8 independent determinations with figure errors shown as standard error of the mean. Cytokine data are given as $\mathrm{pg} / \mathrm{ml}$; C-reactive protein data as $\mu \mathrm{g} / \mathrm{ml}$; and TBARS, AOPP, and GSH as $\mu \mathrm{M}$. Data were statistically analyzed by two-way ANOVA using the variables of implanted metal and time from implant followed by Sidak's multiple comparisons test where each metal implant group within a time from implant is compared back to the corresponding
Ta-implanted group value. Analyses were performed using GraphPad Prism Software (version 9.2.0, La Jolla, CA, USA). In all cases, $p$ values $<0.05$ were considered significant.

\section{Results}

Cytokine levels in the collected rat serum were determined using the Meso Scale Discovery rat proinflammatory marker kit. Cytokines assessed included IFN- $\gamma$, IL-1 $\beta$, IL-4, IL-5, IL6 , KC/GRO, IL-10, IL-13, and TNF- $\alpha$. Serum IL- $1 \beta$ levels were consistently below the limit of detection for all metal implantation groups and thus are not presented here. Figure 1 shows the level of IFN- $\gamma$ in the serum obtained from rats implanted with metals for 1, 3, 6, and 12 months. Overall, IFN- $\gamma$ levels are highest across the board in the 1month cohort with the $\mathrm{Cu}, \mathrm{Al}$, and $\mathrm{Pb}$ groups showing significantly higher IFN- $\gamma$ levels than the control. Conversely, the 1-month DU cohort's IFN- $\gamma$ serum levels are significantly lower than those of the control. At 3 months postimplantation, serum IFN- $\gamma$ levels are also significantly higher in the $\mathrm{Ni}$, Co, and Fe groups as well as still being significantly elevated in the $\mathrm{Cu}, \mathrm{Al}$, and $\mathrm{Pb}$ groups. At 3 months, levels in 




(a)

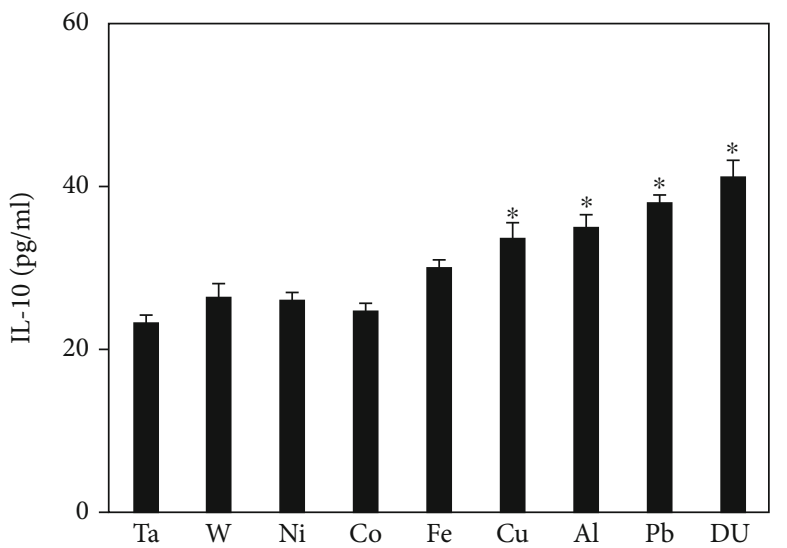

(c)



(b)

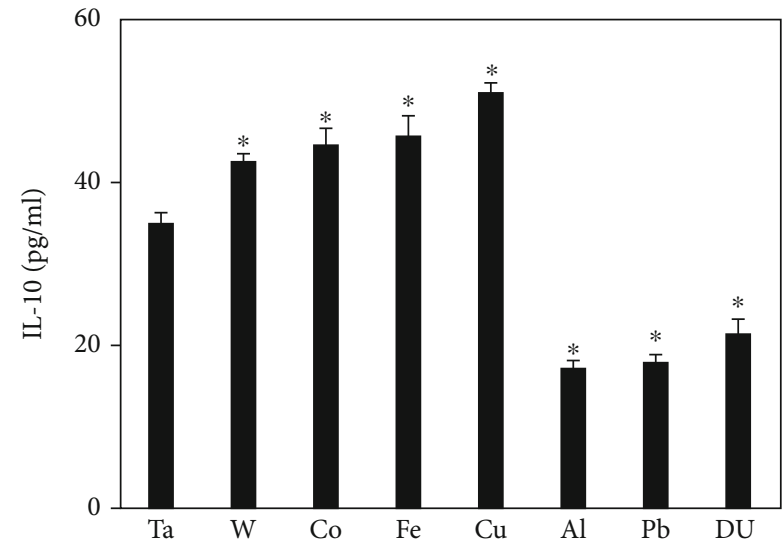

(d)

FIGURE 5: IL-10 levels in serum from metal-implanted rats: (a) 1 month postimplantation; (b) 3 months postimplantation; (c) 6 months postimplantation; (d) 12 months postimplantation. Data represent the mean of 8 independent determinations. Error bars are standard error of the mean. Note: the $12 \mathrm{M} \mathrm{Ni}$ cohort was euthanized at approximately $6 \mathrm{M}$ as a result of tumor formation. An $*$ indicates a post hoc test between Ta- and target-metal animals at that time point $(p<0.05)$.

the DU group were no different than those in the control. By 6 months postimplantation, the only metal group that had significantly higher IFN- $\gamma$ serum levels was the Fe cohort. A similar situation was observed at 12 months postimplantation with only the $\mathrm{Fe}$ and $\mathrm{Cu}$ groups demonstrating significantly higher serum IFN- $\gamma$ levels than the control.

Serum IL-4 levels across the four time points are shown in Figure 2. At 1 month postimplantation, only the $\mathrm{Pb}$ and DU groups are significantly different from the control, with $\mathrm{Pb}$ being higher and $\mathrm{DU}$ lower. At 3 months postimplantation, the DU cohort was no different than the control while the $\mathrm{Pb}$ group remained elevated and was joined by the $\mathrm{Ni}$, $\mathrm{Cu}$, and $\mathrm{Al}$ groups as well. By 6 months postimplantation, $\mathrm{Ni}$ had returned to control levels while $\mathrm{Cu}, \mathrm{Al}$, and $\mathrm{Pb}$ serum IL-4 levels remained significantly elevated with the Fe and DU groups also showing elevated levels of serum IL-4. By 12 months postimplantation, IL-4 levels remained elevated in the $\mathrm{Fe}$ and $\mathrm{Cu}$ groups. The Co cohort also demonstrated significantly higher serum IL-4 levels over the control, but the $\mathrm{Al}$ and $\mathrm{Pb}$ groups were significantly lower than the control while the DU cohort was not significantly different than the control.
Serum IL-5 levels in the metal-implanted groups showed no significant differences at the 1-, 3-, and 6-month time points (Figure 3). However, at 12 months postimplantation, the $\mathrm{Co}, \mathrm{Fe}$, and $\mathrm{Cu}$ groups all showed significantly higher serum levels of IL- 5 when compared to the control.

Figure 4 shows IL-6 levels in serum from metalimplanted rats. At 1 month, the $\mathrm{Cu}$ group was significantly higher and the DU group significantly lower than the control. By 3 months, both groups were no different than the control, but the $\mathrm{Co}, \mathrm{Al}$, and $\mathrm{Pb}$ groups showed significantly higher serum levels of IL- 6 than the control. At 6 months postimplantation, the $\mathrm{Al}$ and $\mathrm{Pb}$ groups remained elevated and were joined by the $\mathrm{Cu}$ and $\mathrm{DU}$ groups while the Co group was not different than the control. The $\mathrm{Cu}$ group remained significantly elevated at the 12-month time point as were the $\mathrm{W}$, $\mathrm{Co}$, and Fe groups. Serum IL-6 levels in the $\mathrm{Pb}$ and $\mathrm{DU}$ groups were not significantly different from those in the control, while levels in the $\mathrm{Al}$ were significantly lower.

Serum IL-10 levels from the metal-implanted rats are shown in Figure 5. At 1 month postimplantation, there were no significant differences from the control except for the DU group which was significantly lower. However, at the 3- 


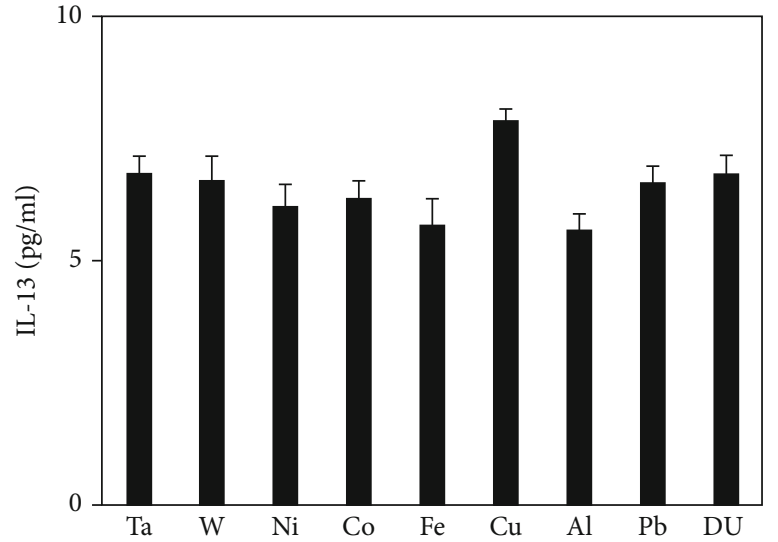

(a)

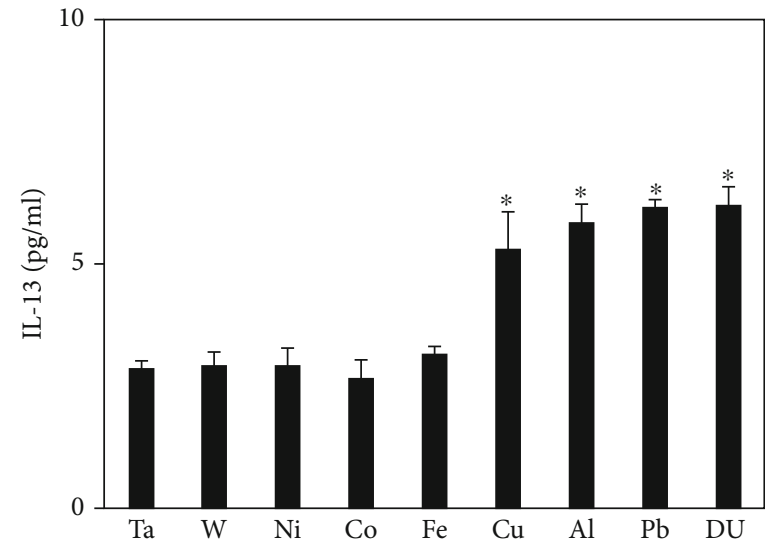

(c)

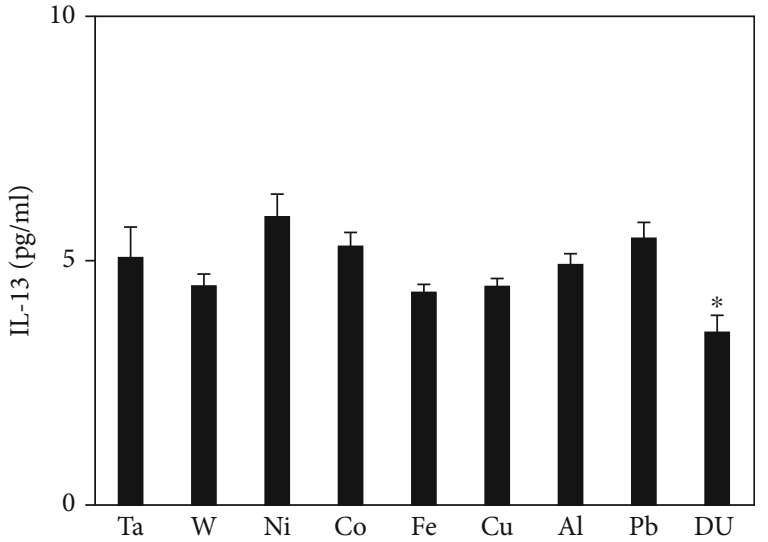

(b)

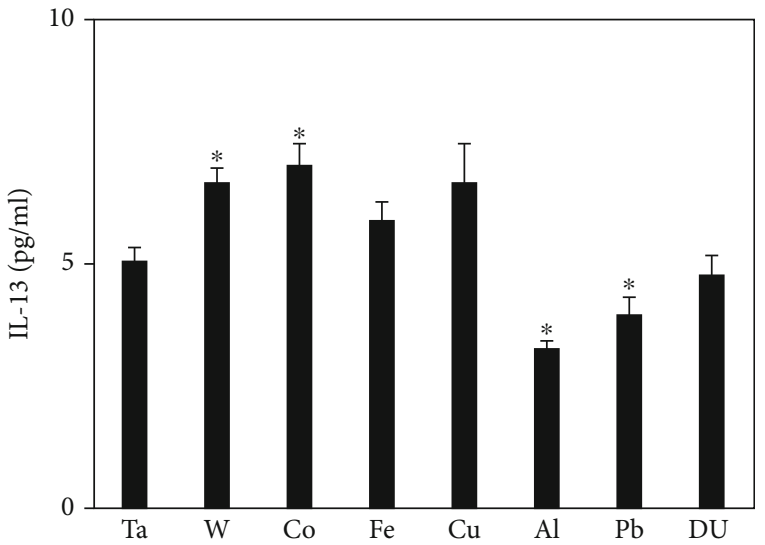

(d)

FiguRe 6: IL-13 levels in serum from metal-implanted rats: (a) 1 month postimplantation; (b) 3 months postimplantation; (c) 6 months postimplantation; (d) 12 months postimplantation. Data represent the mean of 8 independent determinations. Error bars are standard error of the mean. Note: the $12 \mathrm{M} \mathrm{Ni}$ cohort was euthanized at approximately $6 \mathrm{M}$ as a result of tumor formation. An $*$ indicates a post hoc test between Ta- and target-metal animals at that time point $(p<0.05)$.

month postimplantation time point, all metal groups showed significantly higher serum IL-10 levels compared to the control, with the exception of the $\mathrm{W}$ group. All metal groups at the 12-month postimplantation time point were significantly different than the control with W, Co, Fe, and $\mathrm{Cu}$ significantly higher and $\mathrm{Al}, \mathrm{Pb}$, and $\mathrm{DU}$ significantly lower.

Figure 6 shows serum IL-13 levels in metal-implanted rats. No significant differences were observed at the 1month postimplantation time point, and only the DU group was significantly lower than the control at the 3-month time point. However, by 6 months postimplantation, the $\mathrm{Cu}, \mathrm{Al}$, $\mathrm{Pb}$, and $\mathrm{DU}$ groups showed significantly elevated serum IL-13 levels compared to the control. By 12 months postimplantation, these four groups were either no different than the control $(\mathrm{Cu}, \mathrm{DU})$ or significantly lower $(\mathrm{Al}, \mathrm{Pb})$. Conversely, the $\mathrm{W}$ and Co groups demonstrated significantly elevated serum IL-13 levels at this time point.

Serum levels of KC/GRO and TNF- $\alpha$ in metal-implanted rats are shown in Figures 7 and 8, respectively. No significant differences from the control were seen in any of the metal groups at any time points for $\mathrm{KC} / \mathrm{GRO}$, while only the 12-month $\mathrm{Al}$ group was significantly different from the control with respect to serum TNF- $\alpha$ levels.

Figure 9 shows the serum levels of C-reactive protein in the metal-implanted groups. Only the 1-month DU and 3month nickel and iron groups exhibited serum C-reactive protein levels significantly higher than the control. However, the 12-month postimplantation $\mathrm{Al}, \mathrm{Pb}$, and $\mathrm{DU}$ groups showed significantly lower serum C-reactive protein as compared to the controls. In fact, the serum levels of C-reactive protein in those groups tended to drop over time while the levels in the other metal-implanted cohorts tended to rise as the animals aged.

The TBARS assay was used as an indicator for lipid peroxidation in this study. As seen in Figure 10, in most of the groups, lipid peroxidation rose over time; however, only the 12-month $\mathrm{Al}$ and $\mathrm{Pb}$ groups were shown to be statistically greater than the control. Somewhat surprisingly, before the TBARS increase observed at 12 months, the 6-month levels in the $\mathrm{Fe}, \mathrm{Cu}, \mathrm{Al}, \mathrm{Pb}$, and $\mathrm{DU}$ groups were significantly lower than those in the control at the same time point.

Oxidative protein damage was assessed with the advanced oxidation protein products assay with the results 


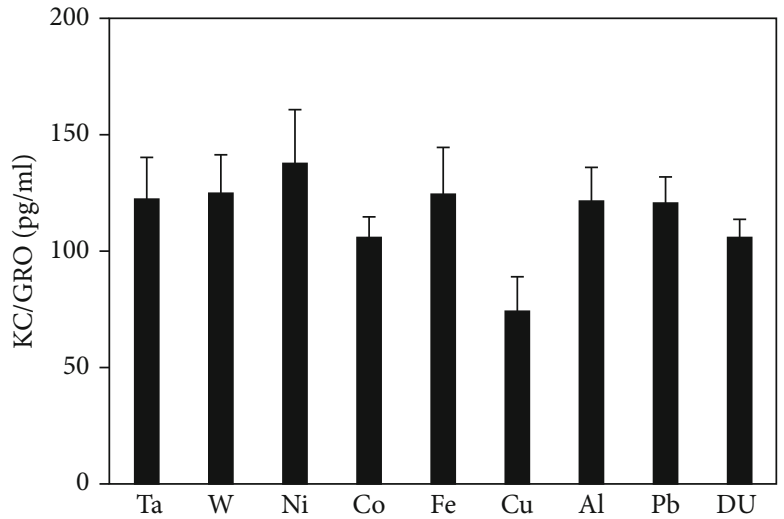

(a)

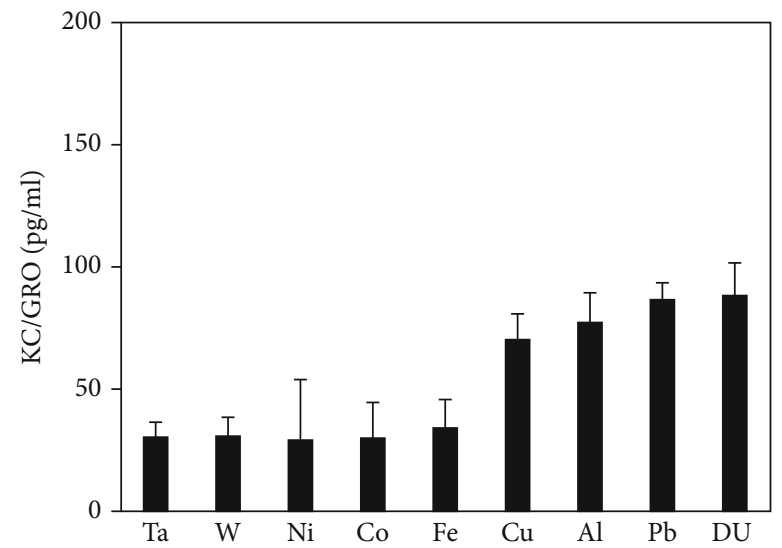

(c)

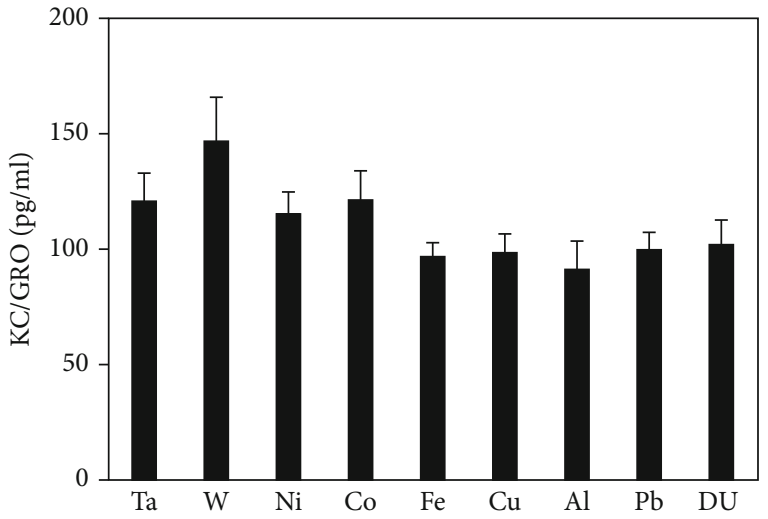

(b)



(d)

FIGURE 7: KC/GRO levels in serum from metal-implanted rats: (a) 1 month postimplantation; (b) 3 months postimplantation; (c) 6 months postimplantation; (d) 12 months postimplantation. Data represent the mean of 8 independent determinations. Error bars are standard error of the mean. Note: the $12 \mathrm{M} \mathrm{Ni}$ cohort was euthanized at approximately $6 \mathrm{M}$ as a result of tumor formation. An $*$ indicates a post hoc test between Ta- and target-metal animals at that time point $(p<0.05)$.

shown in Figure 11. Similar to what was seen with lipid peroxidation, protein oxidation generally increased in all groups over time with the only exception being the 12-month DU group which was significantly lower than the control.

In light of the implanted metal effects on lipid peroxidation products found in the serum, we also measured the total glutathione levels in the serum to determine if metal implantation had any effect on antioxidant capacity. As seen in Figure 12, there were no significant differences between any on the metal implantation groups and control at any of the time points assessed.

\section{Discussion}

The ability to identify potential adverse health effects resulting from embedded metals in the body is an area of increasing urgency. With an estimated 40,000 U.S. military personnel with retained metal fragments from the conflicts in Iraq and Afghanistan, as well as an untold number of civilian casualties, the capability to detect early changes as a result of embedded metals is the key to initiating prompt medical intervention strategies, including more extensive surgical removal of the embedded metal if warranted. As a part of our larger multi-institute study on the health effects of embedded fragments, we report here our investigations on cytokine and oxidative damage markers in the serum of laboratory rats implanted with pellets of military-relevant metals. We have previously reported that, with the exception of rhabdomyosarcoma formation in both the $\mathrm{Ni}$ - and $\mathrm{Co}$ implanted groups, no metal-induced damage was observed by histopathological examination of the gastrocnemius by a board-certified veterinary pathologist [35]. Rhabdomyosarcoma induction by embedded $\mathrm{Ni}$ pellets necessitated early euthanasia of the 12-month Ni cohort based on IACUC criteria while tumor formation in the Co-implanted rats did not reach this level of severity and such were not euthanized early. Another unexpected finding previously reported was the migration and expulsion of the $\mathrm{Cu}$ pellets through the skin over the gastrocnemius shortly after 3 months of implantation [35]. Again, no noticeable muscle damage was observed via histopathology assessment. As a result, we were interested in determining whether serum markers of oxidative stress and/or damage might indicate potential adverse health effects.

Cytokines are low molecular weight, nonstructural proteins secreted by cells and having a major role in regulating 


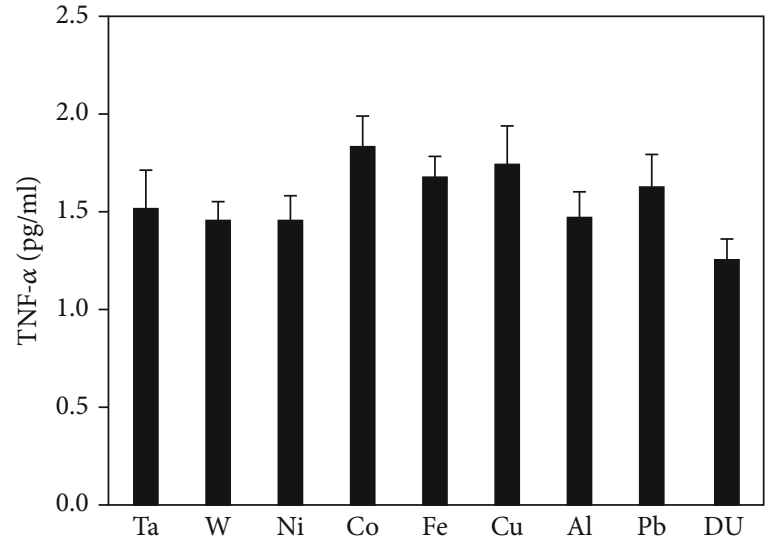

(a)

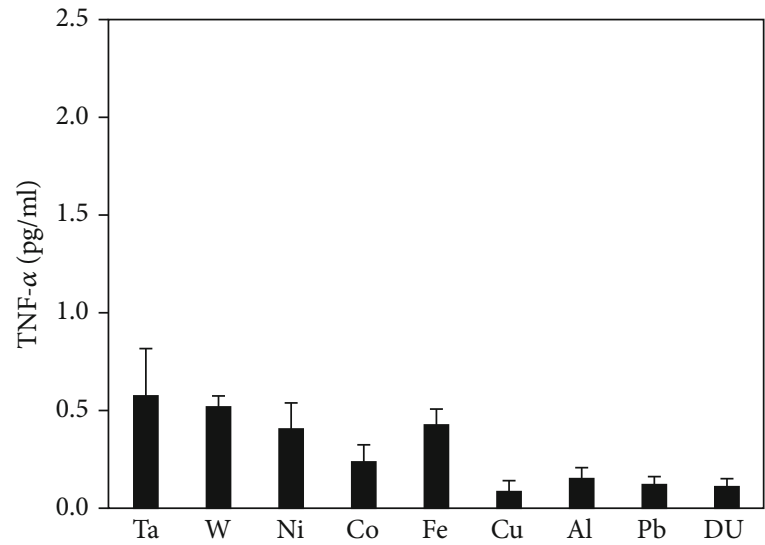

(c)

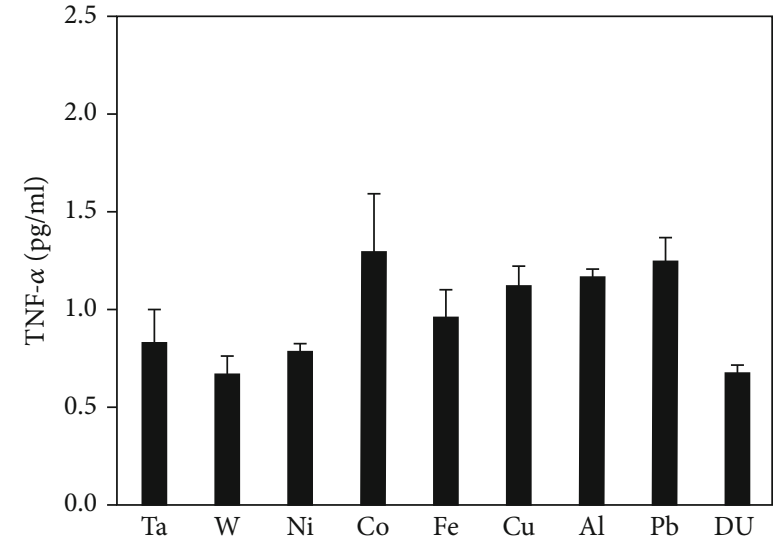

(b)

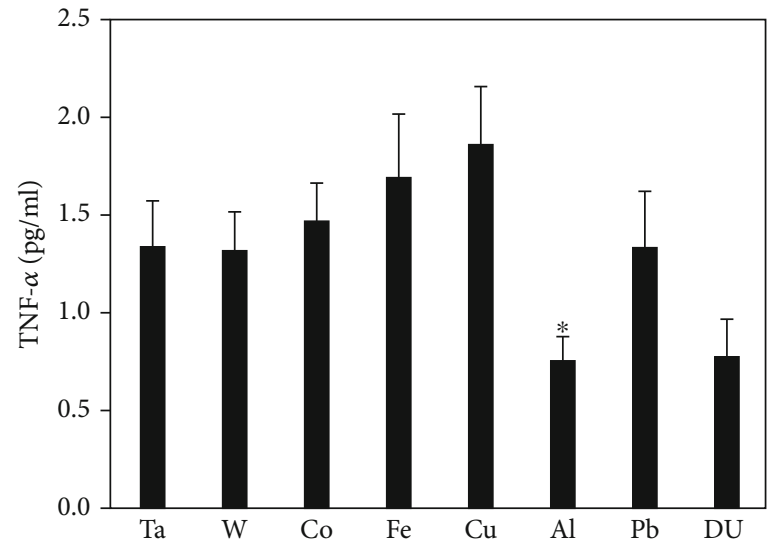

(d)

FiguRE 8: TNF- $\alpha$ levels in serum from metal-implanted rats: (a) 1 month postimplantation; (b) 3 months postimplantation; (c) 6 months postimplantation; (d) 12 months postimplantation. Data represent the mean of 8 independent determinations. Error bars are standard error of the mean. Note: the $12 \mathrm{M} \mathrm{Ni}$ cohort was euthanized at approximately $6 \mathrm{M}$ as a result of tumor formation. An $*$ indicates a post hoc test between Ta- and target-metal animals at that time point $(p<0.05)$.

inflammation and immunity. Although there have been reports in the literature investigating cytokine levels after the failure of knee and hip replacements [18-20, 36-38] as well as a result of acute muscle injury $[39,40]$, there have been no reports on perturbations in serum cytokine levels from embedded metal fragments such as those suffered in armed conflict. In this study, we assessed the serum levels of a variety of biomarkers linked to the induction and resolution of inflammation. Some of the measured cytokines showed little to no difference between the metal-implanted animals and control. For example, IL- $1 \beta$ levels in practically all cases were below the limit of detection of the assay method. Other markers, such as KC/GRO, showed no statistical differences between control and metal-implanted rats. Further, serum TNF- $\alpha$ levels were only significantly lower in the 12-month $\mathrm{Al}$ cohort, with no other statistically significant differences observed. However, there were significant differences in many of the other cytokines measured.

IFN- $\gamma$, a potent macrophage activator, was significantly elevated in the serum of most of the metal-implanted rats particularly at the 3-month time point. In most cases, levels revert to normal, but in the case of the $\mathrm{Fe}$ and $\mathrm{Cu}$ cohorts, they remain elevated for extended periods. The fact that $\mathrm{Fe}$ and $\mathrm{Cu}$ can catalyze the Fenton and Haber-Weiss reactions $[41,42]$ to produce reactive oxygen species may play a role in the enhanced elevation of IFN- $\gamma$, but this hypothesis requires further investigation.

Serum IL-5 levels were significantly higher in the Co, Fe, and $\mathrm{Cu}$ cohorts but only in the 12-month postimplantation groups. IL-5 has been shown to be elevated in synovial fluid from patients with failed $\mathrm{Co} / \mathrm{Cr} / \mathrm{Mo}$ metal-on-metal hip arthroplasties [36]. IL-5 has a variety of roles with B-cell differentiation being the most prominent. IL-5 levels are also elevated in serum from Ni-allergic individuals [43]; however, implantation of Ni pellets had no effect on IL-5 levels in the serum of the rats.

IL-6 is classified as a proinflammatory cytokine. However, depending upon the experimental situation, IL-6 has been ascribed to both pro- and anti-inflammatory properties $[40,43-45]$. Some investigators have used the term "inflammation-responsive" as it does not directly induce inflammation and, in fact, is able to mediate antiinflammatory responses [40, 46-49]. In our model, all of the implanted test metals, except for $\mathrm{Ni}$, resulted in significantly 


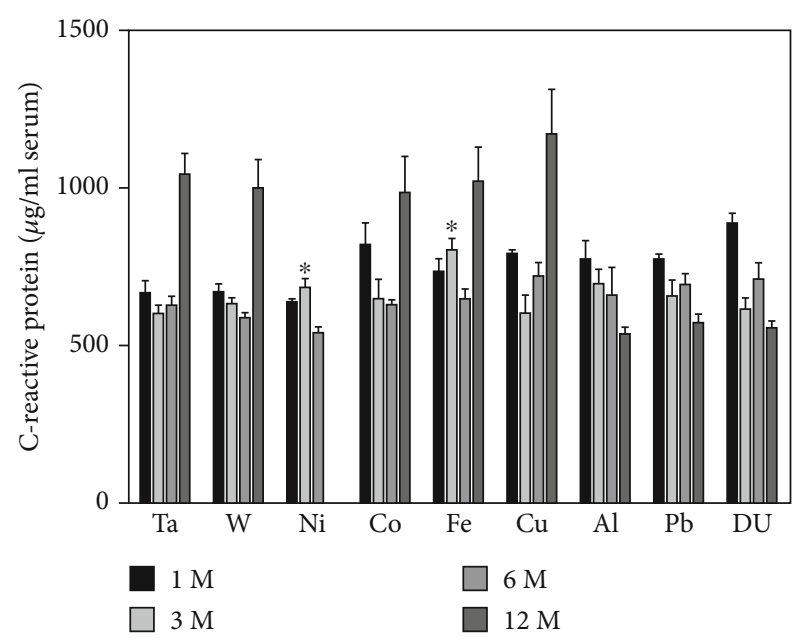

Figure 9: C-reactive protein levels in serum from metal-implanted rats. Data represent the mean of 8 independent determinations. Error bars are standard error of the mean. Note: the $12 \mathrm{M} \mathrm{Ni}$ cohort was euthanized at approximately $6 \mathrm{M}$ as a result of tumor formation. An $*$ indicates a post hoc test between Ta- and targetmetal animals at that time point $(p<0.05)$.

elevated serum levels of IL-6 usually starting at the 3-month postimplantation time point, and in some case, serum levels of IL-6 were still elevated at the 12-month time point.

The other cytokines investigated (IL-4, IL-10, and IL-13) have all been identified as having anti-inflammatory properties and a role in the repair of muscle damage [40]. The patterns for these four cytokines are remarkably similar across most of the metal implantation groups with significantly higher serum levels in the 3- and 6-month time points. For some metals such as $\mathrm{Co}, \mathrm{Fe}$, and $\mathrm{Cu}$, the levels remain elevated at the 12 -month time point while for others $(\mathrm{Al}, \mathrm{Pb}$, and DU), the levels decrease to well below control values. Although beyond the scope of this project, it would be informative to extend the collection time points to cover the entire lifespan of the rat since many of the adverse health effects of embedded shrapnel from war wounds reported in the literature occur many years after the initial injury.

Taken together, these data indicate that, even in the absence of overt histopathological damage, embedded metal fragments can affect serum cytokine levels. Many, but not all, of the cytokines assessed were significantly elevated in serum. Somewhat surprisingly, only IFN- $\gamma$ and IL-4 were significantly elevated at 1 month postimplantation: IFN- $\gamma$ for $\mathrm{Cu}$ and $\mathrm{Al}$ and $\mathrm{IL}-4$ for $\mathrm{Pb}$. On the other hand, rats implanted with DU pellets showed significantly decreased levels of IFN- $\gamma$, IL-4, IL-6, IL-10, and IL-13 at the early time points before reaching significantly higher levels at the later experimental points, suggesting that DU inhibits cytokine expression shortly after implantation by an as yet unidentified mechanism.

Oxidative stress occurs when the production of free radicals overwhelms the cell's antioxidant defense systems. This can result in the oxidative damage of DNA, lipids, and proteins. This damage can potentially result in the induction of inflammation, genotoxicity, and carcinogenesis. Although information on embedded metal fragments is lacking, expo-

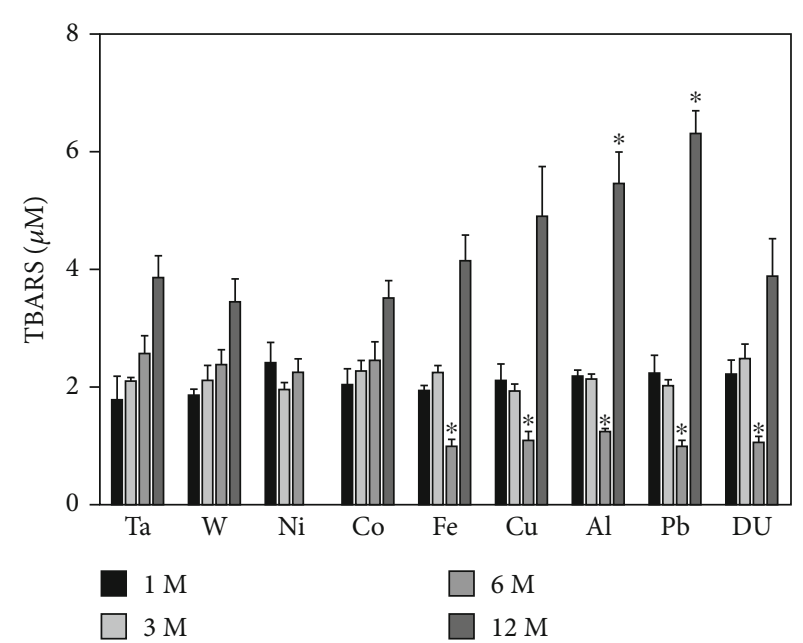

Figure 10: Assessment of lipid peroxidation in serum from metalimplanted rats. Data represent the mean of 8 independent determinations. Error bars are standard error of the mean. Note: the $12 \mathrm{M} \mathrm{Ni}$ cohort was euthanized at approximately $6 \mathrm{M}$ as a result of tumor formation. An $*$ indicates a post hoc test between Ta- and target-metal animals at that time point $(p<0.05)$.

sure to metals in a variety of experimental systems has been shown to result in the induction of oxidative stress [50-53]. Even though many metals have been shown to induce oxidative damage, $\mathrm{Cu}$ and $\mathrm{Fe}$ have received the most study because of their endogenous nature and ability to participate in the Fenton and Haber-Weiss reactions [41, 42]. Both $\mathrm{Cu}$ and $\mathrm{Fe}$ have been shown to generate reactive oxygen and nitrogen species resulting in oxidative damage that depletes cellular antioxidant defenses and adversely affects the ability of the cell to maintain energy homeostasis [54-56]. Depletion of cellular antioxidant defenses also leads to oxidative damage to proteins, lipids, and DNA [57-60].

C-reactive protein is a liver protein that has been identified as a biomarker of low-level inflammation. Previously published research has indicated that serum C-reactive protein levels correlate positively with $\mathrm{Cu}$ serum levels and negatively with selenium levels [61]. We did not see any significant effect of $\mathrm{Cu}$ implantation on C-reactive protein levels at any of the time points examined. At 3 months postimplantation, levels were significantly higher in the $\mathrm{Ni}$ and $\mathrm{Fe}$ cohorts. For the $\mathrm{W}, \mathrm{Co}, \mathrm{Fe}$, and $\mathrm{Cu}$ groups, serum $\mathrm{C}$ reactive protein levels tended to rise as the animal aged. Conversely, in the $\mathrm{Al}, \mathrm{Pb}$, and $\mathrm{DU}$ cohorts, the levels trended downward over time and at 12 months postimplantation were significantly lower than those in the control.

Metals have been shown to affect lipid peroxidation [62, 63] and can be loosely grouped into those that undergo redox-cycling reactions and those that are redox-inactive whose major effect is depleting the antioxidant glutathione [64]. Metals in the former category include $\mathrm{Fe}, \mathrm{Cu}$, and $\mathrm{Co}$ while those in the latter include $\mathrm{Ni}$ and $\mathrm{Pb}$. Using the TBARS assay to assess lipid peroxidation in the serum of metalimplanted rats, we found that while lipid peroxidation generally tended to increase over the entire experimental period for all metals with both the $\mathrm{Al}$ and $\mathrm{Pb}$ 12-month groups demonstrating significantly elevated levels of lipid 


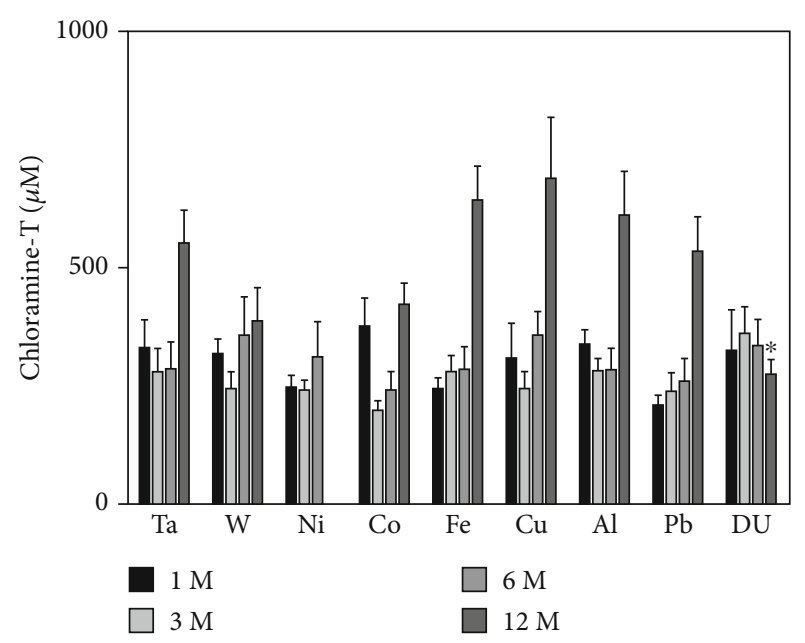

Figure 11: Advanced oxidation protein products in serum from metal-implanted rats. Data represent the mean of 8 independent determinations. Error bars are standard error of the mean. Note: the $12 \mathrm{M} \mathrm{Ni}$ cohort was euthanized at approximately $6 \mathrm{M}$ as a result of tumor formation. An $*$ indicates a post hoc test between Ta- and target-metal animals at that time point $(p<0.05)$.

peroxidation over the control, there were significantly lower levels at the 6-month time point for $\mathrm{Fe}, \mathrm{Cu}, \mathrm{Al}, \mathrm{Pb}$, and $\mathrm{DU}$ groups. Although $\mathrm{Pb}$ and $\mathrm{Al}$ are considered redox-inactive, both have been shown to increase lipid peroxidation in a variety of experimental systems. In a rat model, oral exposure to $\mathrm{Pb}$ increased lipid peroxidation levels in blood plasma and salivary glands [65]. $\mathrm{Pb}$ exposure also induced lipid peroxidation in the blood, kidney, and liver [66] with the increase due to a decrease in glutathione and other cellular antioxidant defenses [67]. $\mathrm{Al}$ exposure also induced lipid peroxidation in a variety of organs [68]. In this case, it is believed that $\mathrm{Al}$ acts as a prooxidant and facilitates oxidative stress through superoxideand endogenous Fe-associated mechanisms [69, 70]. Using a freshwater snail model and exposure to several heavy metals, Mnkandla et al. [71] showed that metal exposure could result, at least temporarily, in a decrease in lipid peroxidation by upregulating the expression of superoxide dismutase, catalase, and glutathione peroxidase, enzymes involved in the cellular antioxidant defense system. It is likely that a similar situation could be occurring in our study with an increase in antioxidant defenses at the 6-month time point followed by depletion or overwhelming of the defenses followed by an increase in lipid peroxidation. An investigation into the metal effects on the expression of the enzymatic antioxidant defenses is beyond the scope of this submission. However, in an earlier report, we showed that 4-hydroxynonenal-modified proteins in the area of the gastrocnemius where the metal pellets were implanted were significantly increased at 12 months postimplantation in the $\mathrm{Fe}, \mathrm{Cu}, \mathrm{Pb}$, and $\mathrm{DU}$ groups suggesting that some, but not all, embedded metals can induce lipid peroxidation [72]. Since several of the test metals are considered "redoxinactive" and are capable of depleting glutathione, we also measured total glutathione levels in serum. Glutathione is the most abundant low molecular weight thiol in cells and plays a major role in antioxidant defense and maintenance of the cellular redox state [73-75]. In particular, it is a key

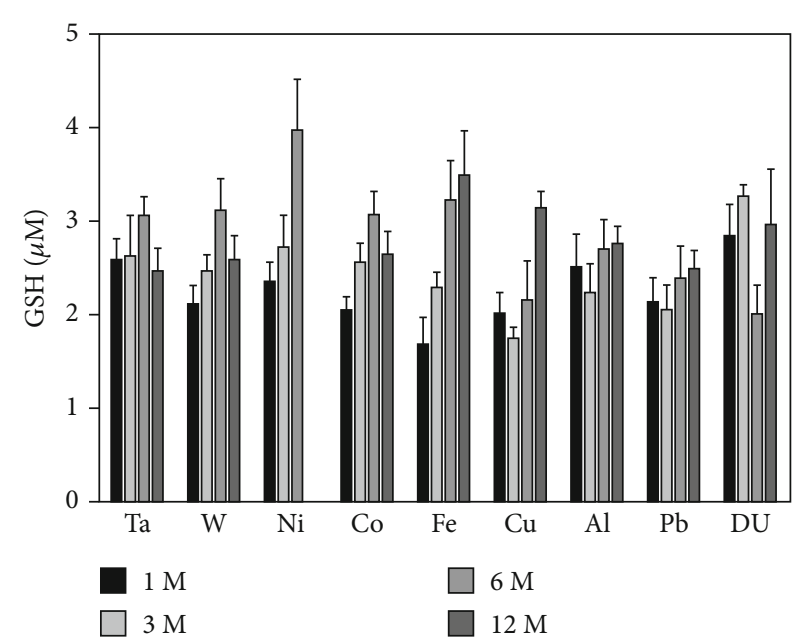

FIGURE 12: Glutathione levels in serum from metal-implanted rats. Data represent the mean of 8 independent determinations. Error bars are standard error of the mean. Note: the $12 \mathrm{M} \mathrm{Ni}$ cohort was euthanized at approximately $6 \mathrm{M}$ as a result of tumor formation. An $*$ indicates a post hoc test between Ta- and targetmetal animals at that time point $(p<0.05)$.

player in the amelioration of metal-induced oxidative stress by maintaining redox balance as well as by chelating metals that contribute to oxidative damage [76]. Despite the important role glutathione plays in regulating metal-induced oxidative stress, we found no significant differences with any of the metals at the time points assessed. We also did not find any significant effect of metals on oxidatively damaged proteins assessed by the advanced oxidation protein products assay. In fact, there was only one value significantly different from the control and that was the 12-month DU group, and it was lower than the control.

\section{Conclusions}

Injuries with embedded metal fragments are an unfortunate consequence of armed conflicts. Technological advances in weapon systems and the insurgent use of improvised explosive devices mean that the types of metal found in these wounds are virtually unlimited. Standard surgical guidance is to leave embedded metals in place except under certain conditions in order to avoid the potential morbidity that extensive surgery can bring. Unfortunately, in many cases, the long-term toxicological properties of embedded metals are not known, further complicating treatment decisions. In this report, we expanded upon our earlier research investigating the health effects of embedded military-relevant metals and showed that the embedded metals can affect serum cytokine profiles. In particular, IFN- $\gamma$, IL-4, IL-5, IL-6, IL-10, and IL-13 all demonstrated metal-induced increases. While C-reactive protein and lipid peroxidation by-products were also affected by the embedded metals, there were no indications of oxidative protein damage and glutathione levels were also not affected. Taken together, the results described suggest that serum cytokine levels may prove useful in developing early detection profiles for identifying potential adverse health effects of various embedded metals. 


\section{Data Availability}

All data supporting the results described are provided within the manuscript.

\section{Ethical Approval}

All procedures involving animals were (a) conducted with maximal possible well-being of the rats, (b) approved by the AFRRI Institutional Animal Care and Use Committee (IACUC) prior to the start of the study under protocol 2016-05-006, and (c) performed in compliance with the guidelines set forth in the Guide for the Care and Use of Laboratory Animals in an Association for Assessment and Accreditation of Laboratory Animal Care- (AAALAC-) accredited facility.

\section{Disclosure}

The views expressed in this article do not reflect the official policy or position of the Armed Forces Radiobiology Research Institute, Uniformed Services University, Department of Defense, or United States Government.

\section{Conflicts of Interest}

The authors declare no conflict of interest with respect to the research, authorship, or publication of this article.

\section{Acknowledgments}

The authors would like to thank Raisa Marshall, Anya Fan, and William Danchanko for their expertise in the pellet implantation surgeries, animal welfare checks, and tissue collection. The project described was supported by the grant Health Effects of Blast Injuries and Embedded Metal Fragments (W81XWH-16-2-0058) from the Peer-Reviewed Medical Research Program of the Congressionally Directed Medical Research Programs (CDMRP).

\section{References}

[1] K. L. Maggio, V. F. Kalasinsky, M. R. Lewin-Smith, and F. G. Mullick, "Wound fragments from cutaneous sites of U.S. military personnel deployed in operation Iraqi Freedom," Dermatologic Surgery, vol. 34, no. 4, pp. 475-482, 2008.

[2] R. P. Symonds, C. Mackay, and P. Morley, "The late effect of grenade fragments," Journal of the Royal Army Medical Corps, vol. 131, no. 2, pp. 68-69, 1985.

[3] D. A. Ligtenstein, J. L. M. Krijnen, B. R. H. Jansen, and F. Eulderink, "Forgotten injury: A late benign complication of an unremoved shrapnel fragment-Case report," Journal of Trauma, vol. 36, no. 4, pp. 580-582, 1994.

[4] S. Eylon, R. Mosheiff, M. Liebergall, E. Wolf, L. Brocke, and A. Peyser, "Delayed reaction to shrapnel retained in soft tissue," Injury: International Journal of the Care of the Injured, vol. 36, no. 2, pp. 275-281, 2005.

[5] Y. Bar and O. Merimsky, "Soft-tissue sarcoma following traumatic injury: case report and review of the literature," Frontiers in Oncology, vol. 7, article 134, 2017.
[6] N. L. Schenck and B. S. Kronman, "Communications," Annals of Otology, Rhinology, and Laryngology, vol. 86, no. 2, p. 259, 1977.

[7] J. Knox and A. Wilkinson, "Shrapnel presenting with symptoms 62 years after wounding," British Medical Journal (Clinical Research Edition), vol. 283, no. 6285, p. 193, 1981.

[8] G. Lindeman, M. J. McKay, K. L. Taubman, and A. M. Bilous, "Malignant fibrous histiocytoma developing in bone 44 years after shrapnel trauma," Cancer, vol. 66, no. 10, pp. 22292232, 1990 .

[9] T. J. Spalding, M. P. Stewart, D. N. Tulloch, and K. M. Stephens, "Penetrating missile injuries in the Gulf War 1991," British Journal of Surgery, vol. 78, no. 9, pp. 1102-1104, 2005.

[10] J. M. Gaitens, M. Condon, K. S. Squibb, J. A. Centeno, and M. A. McDiarmid, "Metal exposure in veterans with embedded fragments from war-related injuries: early findings from surveillance efforts," Journal of Occupational and Environmental Medicine, vol. 59, no. 11, pp. 1056-1062, 2017.

[11] "Policy on Analysis of Metal Fragments Removed from Department of Defense Personnel (Policy\#:07-029, Date: 12/ 18/2007)," November 2021, https://www.health.mil/MilitaryHealth-Topics/Health-Readiness/EnvironmentalExposures?page=2\#pagingAnchor.

[12] "Screening and Evaluation Protocol for Veterans with Embedded Fragments Who Served in Iraq and/or Afghanistan PostSeptember 11, 2001 (April 6, 2017)," November 2021, https://www.va.gov/VHAPublications/ViewPublication .asp?pub_ID=5372.

[13] R. Osawa, R. Abe, D. Inokuma et al., "Chain saw blade granuloma: reaction to a deeply embedded metal fragment," Archives of Dermatology, vol. 142, no. 8, pp. 1079-1080, 2006.

[14] H. Saruwatari, R. Kamiwada, S. Matsushita, T. Hashiguchi, K. Kawai, and T. Kanekura, "Tungsten granuloma attributable to a piece of lawn-mower blade," Clinical and Experimental Dermatology, vol. 34, no. 7, pp. e268-e269, 2009.

[15] J. J. Jacobs, N. J. Hallab, R. M. Urban, and A. K. Skipor, "Metal degradation products: a cause for concern in metal-metal bearings?," Clinical Orthopaedics and Related Research, vol. 417, pp. 139-147, 2003.

[16] G. M. Keegan, I. D. Learmonth, and C. P. Case, "Orthopaedic metals and their potential toxicity in the arthroplasty patient," Journal of Bone and Joint Surgery - British Volume, vol. 89-B, no. 5, pp. 567-573, 2007.

[17] K. A. Fox, T. M. Phillips, J. H. Yanta, and M. G. Abesamis, "Fatal cobalt toxicity after total hip arthroplasty revision for fractured ceramic components," Clinical Toxicology, vol. 54, no. 9, pp. 874-877, 2016.

[18] R. J. Christiansen, H. J. Münch, C. M. Bonefeld et al., "Cytokine Profile in patients with aseptic loosening of total hip replacements and its relation to metal release and metal allergy," Journal of Clinical Medicine, vol. 8, no. 8, p. 1259, 2019.

[19] F. Eltit, N. Mohammad, I. Medina et al., "Perivascular lymphocytic aggregates in hip prosthesis-associated adverse local tissue reactions demonstrate Th1 and Th2 activity and exhausted $\mathrm{CD}^{+}$cell responses," Journal of Orthopaedic Research, vol. 39, no. 12, pp. 2581-2594, 2021.

[20] P. Thomas, C. von der Helm, C. Schopf et al., "Patients with intolerance reactions to total knee replacement: combined assessment of allergy diagnostics, periprosthetic histology, and peri-implant cytokine expression pattern," BioMed 
Research International, vol. 2015, Article ID 910156, 9 pages, 2015.

[21] H. G. Anlar, M. Bacanli, S. İritaş et al., "Effects of occupational silica exposure on oxidative stress and immune system parameters in ceramic workers in Turkey," Journal of Toxicology and Environmental Health Part A Current Issues, vol. 80, no. 13-15, pp. 688-696, 2017.

[22] National Research Council, Guide for the Care and Use of Laboratory Animals, The National Academies Press, Washington, DC, Eighth edition, 2011.

[23] C. A. Castro, K. A. Benson, V. Bogo et al., Establishment of an animal model to evaluate the biological effects of intramuscularly embedded depleted uranium fragments. Technical Report 96-3, Armed Forces Radiobiology Research Institute, Bethesda, MD, USA, 1996.

[24] A. D. Hockley, J. H. Goldin, M. J. C. Wake, and J. Iqbal, "Skull repair in children," Pediatric Neurosurgery, vol. 16, no. 4-5, pp. 271-275, 1990.

[25] C. B. Johansson, H. A. Hansson, and T. Albrektsson, "Qualitative interfacial study between bone and tantalum, niobium or commercially pure titanium," Biomaterials, vol. 11, no. 4, pp. 277-280, 1990.

[26] E. P. Strecker, B. Hagen, D. Liermann, B. Schneider, H. R. D. Wolf, and J. Wambsganss, "Iliac and femoropopliteal vascular occlusive disease treated with flexible tantalum stents," Cardiovascular and Interventional Radiology, vol. 16, no. 3, pp. 158164, 1993.

[27] T. C. Pellmar, A. F. Fuciarelli, J. W. Ejnik et al., "Distribution of uranium in rats implanted with depleted uranium pellets," Toxicological Sciences, vol. 49, no. 1, pp. 29-39, 1999.

[28] F. F. Hahn, R. A. Guilmette, and M. D. Hoover, "Implanted depleted uranium fragments cause soft tissue sarcomas in the muscles of rats," Environmental Health Perspectives, vol. 110, no. 1, pp. 51-59, 2002.

[29] J. F. Kalinich, C. A. Emond, T. K. Dalton et al., "Embedded weapons-grade tungsten alloy shrapnel rapidly induces metastatic high-grade rhabdomyosarcomas in F344 rats," Environmental Health Perspectives, vol. 113, no. 6, pp. 729-734, 2005.

[30] N. Percie du Sert, V. Hurst, A. Ahluwalia et al., "The ARRIVE guidelines 2.0: updated guidelines for reporting animal research," PLoS Biology, vol. 18, no. 7, article e3000410, 2020.

[31] C. A. Emond, V. B. Vergara, E. D. Lombardini, S. R. Mog, and J. F. Kalinich, "Induction of rhabdomyosarcoma by embedded military-grade tungsten/nickel/cobalt not by tungsten/nickel/ iron in the B6C3F1 mouse," International Journal of Toxicology, vol. 34, no. 1, pp. 44-54, 2015.

[32] J. F. Hoffman, V. B. Vergara, A. X. Fan, and J. F. Kalinich, "Effect of embedded metal fragments on urinary metal levels and kidney biomarkers in the Sprague-Dawley rat," Toxicology Reports, vol. 8, pp. 463-480, 2021.

[33] J. F. Hoffman, V. B. Vergara, and J. F. Kalinich, "Brain regionand metal-specific effects of embedded metals in a shrapnel wound model in the rat," Neurotoxicology, vol. 83, pp. 116128, 2021.

[34] American Veterinary Medical Association (AVMA), AVMA Guidelines on EuthanasiaOctober 2021, https://www.avma .org/sites/default/files/2020-02/Guidelines-on-Euthanasia2020.pdf.

[35] Y. Wen, I. J. Vechetti, A. P. Alimov et al., "Time-course analysis of the effect of embedded metal on skeletal muscle gene expression," Physiological Genomics, vol. 52, no. 12, pp. 575587, 2020.

[36] G. Singh, J. V. Nuechtern, H. Meyer et al., "Particle characterisation and cytokine expression in failed small-diameter metalon-metal total hip arthroplasties," Bone and Joint Journal, vol. 97-B, no. 7, pp. 917-923, 2015.

[37] P. Thomas, P. Hisgen, H. Kiefer et al., "Blood cytokine pattern and clinical outcome in knee arthroplasty patients: comparative analysis 5 years after standard versus "hypoallergenic" surface coated prosthesis implantation," Acta Orthopaedica, vol. 89, no. 6, pp. 646-651, 2018.

[38] T. M. Pham, L. H. Frich, K. L. Lambertsen, S. Overgaard, and H. Schmal, "Elevation of inflammatory cytokines and proteins after intra-articular ankle fracture: a cross-sectional study of 47 ankle fracture patients," Mediators of Inflammation, vol. 2021, Article ID 8897440, 9 pages, 2021.

[39] J. M. Peake, K. Suzuki, M. Hordern, G. Wilson, K. Nosaka, and J.S. Coombes, "Plasma cytokine changes in relation to exercise intensity and muscle damage," European Journal of Applied Physiology, vol. 95, no. 5-6, pp. 514-521, 2005.

[40] A. Philippou, M. Maridaki, A. Theos, and M. Koutsilieris, "Cytokines in muscle damage," Advances in Clinical Chemistry, vol. 58, pp. 49-87, 2012.

[41] C. C. Winterbourn, "Toxicity of iron and hydrogen peroxide: the Fenton reaction," Toxicology Letters, vol. 82-83, pp. 969974, 1995.

[42] J. P. Kehrer, "The Haber-Weiss reaction and mechanisms of toxicity," Toxicology, vol. 149, no. 1, pp. 43-50, 2020.

[43] R. Klein, M. Schwenk, and D. M. Templeton, "Cytokine profiles in human exposure to metals (IUPAC Technical Report)," Pure and Applied Chemistry, vol. 78, no. 11, pp. 2155-2168, 2006.

[44] A. Steensberg, "The role of IL-6 in exercise-induced immune changes and metabolism," Exercise Immunology Review, vol. 9, pp. 40-47, 2003.

[45] G. C. Li, C. Zhang, L. He et al., "Association of extracellular superoxide dismutase (EC-SOD) polymorphisms with risk of type 2 diabetes mellitus in a Chinese Han population," International Journal of Clinical and Experimental Pathology, vol. 10, no. 12, pp. 11819-11827, 2017.

[46] B. K. Pedersen and L. Hoffman-Goetz, "Exercise and the immune system: regulation, integration, and adaptation," Physiological Reviews, vol. 80, no. 3, pp. 1055-1081, 2000.

[47] B. K. Pedersen, T. C. A. Åkerström, A. R. Nielsen, and C. P. Fischer, "Role of myokines in exercise and metabolism," Journal of Applied Physiology, vol. 103, no. 3, pp. 1093-1098, 2007.

[48] C. Brandt and B. K. Pedersen, "The Role of Exercise-Induced Myokines in Muscle Homeostasis and the Defense against Chronic Diseases," Journal of Biomedicine and Biotechnology, vol. 2010, Article ID 520258, 6 pages, 2010.

[49] H. Tilg, C. A. Dinarello, and J. W. Mier, "IL-6 and APPs: antiinflammatory and immunosuppressive mediators," Immunology Today, vol. 18, no. 9, pp. 428-432, 1997.

[50] R. M. Harris, T. D. Williams, N. J. Hodges, and R. H. Waring, "Reactive oxygen species and oxidative DNA damage mediate the cytotoxicity of tungsten-nickel-cobalt alloys in vitro," Toxicology and Applied Pharmacology, vol. 250, no. 1, pp. 19-28, 2011.

[51] S. Agrawal, P. Bhatnagar, and S. J. S. Flora, "Changes in tissue oxidative stress, brain biogenic amines and acetylcholinesterase following co-exposure to lead, arsenic and mercury in 
rats," Food and Chemical Toxicology, vol. 86, pp. 208-216, 2015.

[52] J. G. Paithankar, S. Saini, S. Dwivedi, A. Sharma, and D. K. Chowdhuri, "Heavy metal associated health hazards: an interplay of oxidative stress and signal transduction," Chemosphere, vol. 262, article 128350, 2021.

[53] H. Cheng, B. Yang, T. Ke et al., "Mechanisms of metal-induced mitochondrial dysfunction in neurological disorders," Toxics, vol. 9, no. 6, p. 142, 2021.

[54] N. Husain and R. Mahmood, "Copper (II) generates ROS and RNS, impairs antioxidant system and damages membrane and DNA in human blood cells," Environmental Science and Pollution Research, vol. 26, no. 20, pp. 20654-20668, 2019.

[55] C. Saporito-Magriñá, R. Musacco-Sebio, J. M. Acosta et al., "Rat liver mitochondrial dysfunction by addition of copper(II) or iron(III) ions," Journal of Inorganic Biochemistry, vol. 166, pp. 5-11, 2017.

[56] M. E. Letelier, S. Sánchez-Jofré, L. Peredo-Silva, J. CortésTroncoso, and P. Aracena-Parks, "Mechanisms underlying iron and copper ions toxicity in biological systems: Prooxidant activity and protein-binding effects," Chemico-Biological Interactions, vol. 188, no. 1, pp. 220-227, 2010.

[57] T. Kocha, M. Yamaguchi, H. Ohtaki, T. Fukuda, and T. Aayagi, "Hydrogen peroxide-mediated degradation of protein: different oxidation modes of copper- and iron-dependent hydroxyl radicals on the degradation of albumin," Biochimica et Biophysica Acta - Protein Structure and Molecular Enzymology, vol. 1337, no. 2, pp. 319-326, 1997.

[58] M. E. Letelier, A. M. Lepe, M. Faúndez et al., "Possible mechanisms underlying copper-induced damage in biological membranes leading to cellular toxicity," Chemico-Biological Interactions, vol. 151, no. 2, pp. 71-82, 2005.

[59] D. R. Lloyd and D. H. Phillips, "Oxidative DNA damage mediated by copper(II), iron(II) and nickel(II) Fenton reactions: evidence for site-specific mechanisms in the formation of double- strand breaks, 8-hydroxydeoxyguanosine and putative intrastrand cross-links," Mutation Research-Fundamental and Molecular Mechanisms of Mutagenesis, vol. 424, no. 1-2, pp. 23-36, 1999.

[60] R. Meneghini, "Iron homeostasis, oxidative stress, and DNA damage," Free Radical Biology and Medicine, vol. 23, no. 5, pp. 783-792, 1997.

[61] Y. Yuan, P. P. Long, K. Liu et al., "Multiple plasma metals, genetic risk and serum C-reactive protein: A metal- metal and gene-metal interaction study," Redox Biology, vol. 29, article 101404, 2020.

[62] K. Jomova and M. Valko, "Advances in metal-induced oxidative stress and human disease," Toxicology, vol. 283, no. 2-3, pp. 65-87, 2011.

[63] O. Sergent, I. Morel, and J. Cillard, "Involvement of metal ions in lipid peroxidation: biological implications," Metal Ions in Biological Systems, vol. 36, pp. 251-287, 1999.

[64] M. Valko, K. Jomova, C. J. Rhodes, K. Kuča, and K. Musílek, "Redox- and non-redox-metal-induced formation of free radicals and their role in human disease," Archives of Toxicology, vol. 90, no. 1, pp. 1-37, 2016.

[65] G. D. Lopes, W. A. B. Aragão, P. C. Nascimento et al., "Effects of lead exposure on salivary glands of rats: insights into the oxidative biochemistry and glandular morphology," Environmental Science and Pollution Research, vol. 28, no. 9, pp. 10918-10930, 2021.
[66] A. Soussi, M. Gargouri, and A. el Feki, "Effects of co-exposure to lead and zinc on redox status, kidney variables, and histopathology in adult albino rats," Toxicology and Industrial Health, vol. 34, no. 7, pp. 469-480, 2018.

[67] V. Matović, A. Buha, D. Đukić-Ćosić, and Z. Bulat, "Insight into the oxidative stress induced by lead and/or cadmium in blood, liver and kidneys," Food and Chemical Toxicology, vol. 78, pp. 130-140, 2015.

[68] I. Staneviciene, L. Ivanov, L. Kursvietiene, and D. Viezeliene, "Short-term effects of aluminum and selenium on redox status in mice brain and blood," Trace Elements and Electrolytes, vol. 34, no. 4, pp. 74-80, 2017.

[69] C. Exley, "The pro-oxidant activity of aluminum," Free Radical Biology and Medicine, vol. 36, no. 3, pp. 380-387, 2004.

[70] F. C. Amador and M. Sancha, "Lipid peroxidation facilitates aluminum accumulation in rat brain synaptosomes," Journal of Toxicology and Environmental Health-Part A-Current Issues, vol. 58, no. 7, pp. 427-435, 1999.

[71] S. M. Mnkandla, N. Basopo, and A. H. Siwela, "The effect of persistent heavy metal exposure on some antioxidant enzyme activities and lipid peroxidation of the freshwater snail, Lymnaea natalensis," Bulletin of Environmental Contamination and Toxicology, vol. 103, no. 4, pp. 551-558, 2019.

[72] J. F. Hoffman, V. B. Vergara, and J. F. Kalinich, "Protein expression in the gastrocnemius muscle of metal-implanted Sprague-Dawley rats," International Journal of Toxicology, 2021.

[73] H. J. Forman, H. Zhang, and A. Rinna, "Glutathione: overview of its protective roles, measurement, and biosynthesis," Molecular Aspects of Medicine, vol. 30, no. 1-2, pp. 1-12, 2009.

[74] A. Pastore, G. Federici, E. Bertini, and F. Piemonte, "Analysis of glutathione: implication in redox and detoxification," Clinica Chimica Acta, vol. 333, no. 1, pp. 19-39, 2003.

[75] F. Q. Schafer and G. R. Buettner, "Redox environment of the cell as viewed through the redox state of the glutathione disulfide/glutathione couple," Free Radical Biology and Medicine, vol. 30, no. 11, pp. 1191-1212, 2001.

[76] M. Jozefczak, T. Remans, J. Vangronsveld, and A. Cuypers, "Glutathione is a key player in metal-induced oxidative stress defenses," International Journal of Molecular Sciences, vol. 13, no. 3, pp. 3145-3175, 2012. 